\title{
Testosterone: a promising adjuvant for a failing heart?
}

\author{
C M Wickramatilake ${ }^{1}$, M R Mohideen ${ }^{2}$, C Pathirana ${ }^{1}$
}

Journal of the Ceylon College of Physicians, 2011, 42, 28-32

\begin{abstract}
Among the chronic diseases which occur with advancing age, chronic heart failure (CHF) remains one of the leading causes of morbidity and mortality worldwide. In patients with nonedematous cachetic heart failure, the neuroendocrine activation creates an imbalance between the anabolism/catabolism and that explains the pathophysiology and symptomatology of CHF. Therefore cardiac cachexia has been identified as an independent prognostic factor in HF. There is overall anabolic hormone deficiency including testosterone which explains the inflammatory cytokine activation and ventricular remodelling in HF. Replacement of physiological doses of testosterone as an immune modulating therapeutic modality has shown promising results. Although, the evidence to demonstrate that the level of testosterone as an independent prognostic marker in these patients are conflicting.
\end{abstract}

Objective: The objective of this review is to summarize the evidence available on the prognostic implications of testosterone hormone in male patients with $\mathrm{CHF}$.

Search strategy and selection criteria: Data for this review were identified by searches of PubMed with the search terms "androgens" or "sex hormones" or "testosterone" in combination with the terms "heart failure" or "chronic heart failure" and "congestive cardiac failure" or in "men". Relevant articles not identified with the search strategy described above, but referenced in the bibliographies of these papers could also be included.

Key words: heart failure, anabolism, catabolism, testosterone, cachexia, prognosis

\footnotetext{
${ }^{1}$ Department of Biochemistry, Faculty of Medicine, University of Ruhuna, Galle, Sri Lanka

${ }^{2}$ Department of Medicine, Faculty of Medicine, University of Ruhuna, Galle, Sri Lanka.
}

$\begin{array}{ll}\text { Abbreviations } \\ \text { HF } & - \text { Heart failure } \\ \text { SHBG } & - \text { Sex hormone binding globulin } \\ \text { CHF } & - \text { Chronic heart failure } \\ \text { NTproBNP } & - \text { N-terminal fragment of prohormone B- } \\ & \quad \text { type natriuretic peptide } \\ \text { RHF } & - \text { Right heart failure } \\ \text { MMP } & - \text { Matrix metalloproteinase } \\ \text { NYHA } & - \text { New York Heart Association } \\ \text { TNF } & - \text { Tumour necrosis factor } \\ \text { GH } & - \text { Growth hormone } \\ \text { IL } & - \text { Interleukin } \\ \text { IGF } & - \text { Insulin like growth factor } \\ \text { mRNA } & - \text { Messenger ribonucleic acid } \\ \text { TT } & - \text { Total testosterone } \\ \text { LVEF } & - \text { Left ventricular ejection fraction } \\ \text { FT } & - \text { Free testosterone } \\ \text { RAA } & - \text { Renin-angiotensin-aldosterone } \\ \text { eFT } & - \text { Estimated free testosterone } \\ \text { ACE } & - \text { Angiotensin converting enzyme } \\ \text { DHEA-S } & - \text { Dehydroepiandrosterone sulfate }\end{array}$

\section{Introduction}

Chronic heart failure (CHF) is a major public health problem causing significant morbidity and mortality ${ }^{1}$. Despite current optimal therapy, patients still experience debilitating symptoms and poor quality of life.

Chronic congestive heart failure is characterized by poor exercise intolerance and dyspnoea and is associated by prolonged neurohormonal activation and proinflammatory cytokine activation which contributes to further deterioration. These mechanisms leads to ananabolic/catabolic imbalance, favouring catabolism, affecting vasodilator capacity and muscle bulk and function ${ }^{2}$. Cachexia is often an unrecognised sign of heart failure and is associated with a poor outcome with no therapy options.

Androgens are an important factor in anabolic function and contribute to muscle strength and function. The imbalance is related to activation of the 
neuroendocrine and inflammatory systems. The anabolic impairment is a multifaceted phenomenon and is related to abnormalities in at least three key anabolic endocrine axes: gonadal, adrenal, and somatotropic. Patients with CHF develop $\mathrm{GH}$ resistance, which results in depletion of IGF-1 in peripheral tissues, thereby promoting skeletal muscle apoptosis ${ }^{3,4}$. A number of different mediators have been implicated in the wasting process, including activation of pro-inflammatory cytokines: tumour necrosis factor, secretion of neurohormones and peptides, including ghrelin, leptin, growth hormone, cortisol, adrenaline, noradrenaline and insulin, and a relative deficiency of micronutrients and macronutrients ${ }^{4,5,6,7}$. Cachexia is more closely associated with hormonal changes in congestive heart failure than symptoms, exercise capacity and left ventricular function ${ }^{8}$.

\section{Role of androgens on heart failure}

With aging, there is progressive decline of the secretion of anabolic hormones including testosterone which may play a role in increasing the risk of chronic disease $^{9}$. The rate of decline is estimated at $1 \%$ per year after the age of 30 years and further lowers in persons with comorbidities and on medications such as steroids. In chronic heart failure, renin-angiotensinaldosterone (RAA) axis is the most affected endocrinal system. It is often accompanied by disturbances in other endocrinal gland secretions. Some studies have shown deficiencies of testosterone, DHEA-S ${ }^{3,4,10}$ and IGF-1 $1^{5,11,12}$, whereas others have not ${ }^{4,12,13}$. It has been hypothesized that these deficiencies are associated with catabolism and aggravate the symptoms of heart failure and possibly has an impact on the disease progression ${ }^{14,15}$. The occurrence of these disorders depends on the degree of heart failure, increasing with the severity of $\mathrm{CHF}^{16}$.

Some studies had revealed that patients with HF have marked deficiencies in all three main anabolic hormonal axes TT, DHEAS, and IGF-1. Testosterone deficiency was most evident in the youngest group of men with CHF ( $<45$ years old). The deficiency of total blood testosterone or free testosterone is an independent marker of poor prognosis in $\mathrm{HF}$ and significant reduction in blood testosterone identifies groups with a higher mortality ${ }^{17}$. A Chinese study reinforces this fact and they have found that the androgen levels in elderly male patients with chronic heart failure were decreased significantly and the level of FT was negatively correlated with degree of heart failure ${ }^{18}$. Another study showed that levels of TT and eFT are decreased in elderly patients with systolic CHF and related to disease severity, but they are not independent predictors for mortality ${ }^{19}$.
One study revealed that, DHEAS and free testosterone were found to be inversely associated with NYHA class ( $p<0.01$ for both). Adjustment for age and NYHA class slightly diminished the prognostic value of the androgens and SHBG, whereas when variables were identified that were associated with both the respective hormone and the outcome and when the level of adjustment was expanded to the full list of those confounders, any prognostic significance of free testosterone, DHEAS or SHBG vanished. Confounders included renal function, the presence of atrial fibrillation, the systolic blood pressure, C-reactive protein, NTproBNP, cortisol, total cholesterol and medication including the use of statins, diuretics and ACE inhibitors ${ }^{20}$.

It has been suggested that a low testosterone level may represent one of the factors contributing to the anabolic/catabolic imbalance characteristically present in many patients with advanced $\mathrm{CHF}^{21}$. However, this causal contribution of testosterone deficiency to worsening outcome in heart failure is still not proven completely as studies on the prognostic significance of serum levels of androgens in chronic heart failure have yielded conflicting results ${ }^{22}$.

\section{Effect of immune mediators on heart failure}

The role of cytokine network in the pathogenesis of $\mathrm{CHF}$ has been gathering research interest. Serum levels of proinflammatory cytokines such as serum tumor necrosis factor (TNF-a) are increased in CHF patients, whereas anti-inflammatory cytokines such as interleukin-10 (IL-10) are decreased. This imbalance in the inflammation and anti-inflammation pathways may result in decreased myocardial contractility, ventricular dilatation, myocardial remodelling, increased cardiac myocyte apoptosis, and cardiac cachexia. TNF-levels are independent predictors of mortality in patients with advanced heart failure ${ }^{23}$. Moreover, TNF- $\alpha$ is one of the most important stimulus of matrix metalloproteinase (MMP), which are the most important proteolysis system in the process of extracellular matrix degradation. Activation of MMP that induces extracellular matrix fibrosis is an important character of ventricular remodelling ${ }^{24}$.

Therefore morphological and functional muscle abnormalities are present in patients with CHF, including fibre atrophy and a prevalence of type II fibres with a predominance of glycolytic over oxidative metabolism. The 'muscle hypothesis' in heart failure proposes that muscle alterations in CHF trigger prolonged neurohumoral and inflammatory activation and abnormal haemodynamic, autonomic and ventilatory responses to exercise; these may contribute 
to heart failure symptomatology and also be involved in the pathophysiology of the heart failure syndrome ${ }^{25}$.

\section{Treatment modalities for CHF}

The traditional approaches of heart failure therapy from symptoms relief through diuretics, vasodilators and inotropic agents have contributed to mortality improvement strategy through use of angiotensin converting enzyme inhibitors, beta-blockers and aldosterone receptor antagonists. However, despite optimal pharmacological therapy, mortality of heart failure remains high suggesting that there could be other pathogenic mechanisms that remain unexplained and thereby unmodified by current therapy. Persistent immune activation and inflammation may represent such 'unmodified mechanisms'.

Immunomodulatory therapy has been applied to restore the inflammatory imbalance in patients with $\mathrm{CHF}$ as a new mode of therapy. The immunomodulatory regimens include some broad-spectrum antiinflammatory agents such as testosterone, immunoglobulin, growth hormone and statins, which have been shown to improve the symptoms and prognosis of $\mathrm{CHF}$ by modulating inflammatory cytokine network ${ }^{26,27}$.

Correcting sex steroid axes in chronic heart failure has largely concentrated on testosterone replacement. Several animal studies and small clinical trials have suggested that testosterone treatment may increase cardiac output, reduce peripheral vascular resistance and improve exercise capacity, but the mechanism of benefit of therapy was unclear; the functional improvement was thought to be due to an effect of testosterone on skeletal muscle rather than on myocardium ${ }^{28,29,30,31,32}$. The beneficial effect appears to be at doses that correct the deficiency as supraphysiological doses have produced unwanted cardiac effects.

Effect of testosterone therapy on ventricular remodelling in $\mathrm{HF}$ is explained by different mechanisms. Testosterone receptors are present in endothelial cells, vascular smooth muscle cells and cardiomyocytes. On the vascular arterial wall, testosterone induces vasodilation; in cardiomyocytes, it induces protein synthesis and hypertrophy ${ }^{21}$.

An important character of ventricular remodelling during heart failure is extracellular matrix fibrosis or over degradations. MMP is the most important proteolysis system in the process of extracellular matrix degradation and play a vital role in ventricular remodelling in chronic heart failure. TNF- $\alpha$ is one of the most important stimulus of MMP ${ }^{33}$. Some studies found that the expression of MMP-9-mRNA in myocardial tissue of the placebo group is increased significantly, whilst testosterone therapy diminishes the myocardial expression of MMP-9-mRNA (34).

Hydroxyproline mainly resides in collagen protein. The hydroxyproline contents in the myocardium reflect the extent of collagen deposition. One study shows that the myocardial hydroxyproline contents are increased following heart failure. Testosterone therapy reduces the myocardial hydroxyproline contents, diminishing excessive proliferation of collagen protein, thus preventing ventricular remodelling. These beneficial effects of testosterone are likely to be mediated by suppressing TNF- $\alpha$ or by down-regulating MMP-9 directly as described above ${ }^{33,34,35}$.

\section{Clinical implications and conclusions}

This review summarises the evidence from epidemiological studies and some clinical trials showing the relationship of testosterone levels to severity and prognosis of heart failure. Although some studies have demonstrated that low serum levels of testosterone relationship to prognosis is confounded by comorbid condition and medication, there are others that indicate androgen deficiency aggravate heart failure symptoms and accelerate disease progression.

The studies reviewed in this article suggest that cardiac cachexia is directly related to the prognosis of heart failure and the symptomatology and the pathophysiology is related to the neuroendocrine activation and the inflammatory process which seemed to be modulated by restoring the anabolic hormones such as testosterone which possess immune modulatory effects. The lack of long-term studies with testosterone replacement makes it difficult to recommend this treatment as yet, but its value as a therapy for augmenting skeletal muscle strength in patients with congestive heart failure is promising.

Although different mechanisms have been described the impact of low testosterone on the outcome of HF and effect of replacement, further studies are required in establishing the mechanism completely. There are also certain issues to resolve: such as a defining cut off values for the deficiency status of testosterone which may lead to underestimate or overestimate the prevalenceof androgen deficiency. Similarly the cause of this high prevalence of biochemical hypogonadism and its significance remains unclear.

In conclusion, in men with heart failure, testosterone was found to be closely associated with disease severity. The prognostic utility of testosterone 
depended on other factors that confounded the relation between testosterone and mortality risk, questioning a causal role of androgens in the pathophysiology and clinical course of heart failure.

To date, testosterone therapy has shown some positive benefits, although there are some concerns over adverse effects. However, large randomized controlled trials are still needed to assess the longterm safety and efficacy. Until such time, testosterone will remain an exciting novel therapy for heart failure that will have to wait its turn to fulfil the rigors of testing.

\section{References}

1. Cleland JG, Khand A, Clark A. The heart failure epidemic: exactly how big is it? Eur Heart J 2001; 22: 623-6.

2. Packer M, Lee WH, Kessler PD, Gottlieb SS, Bernstein JL, Kukin ML. Role of neurohormonal mechanisms in determining survival in patients with severe chronic heart failure. Circulation 1987; 75: IV80-IV92.

3. Anker SD, Chua TP, Ponikowski P, Harrington D, Swan JW, Kox WJ, Poole-Wilson PA, Coats AJ . Hormonal changes and catabolic/anabolic imbalance in chronic heart failure and their importance in cardiac cachexia. Circulation 1997; 96: 526-34.

4. Anker SD, Clark AL, Kemp M, Salsbury C, Teixeira MM, Hellewell PG, Coats AJ. Tumor necrosis factor and steroid metabolism in chronic heart failure: possible relation to muscle wasting. J Am Coll Cardiol 1997; 30: 997-1001.

5. Niebauer J, Pflaum CD, ClarkAL, Strasburger CJ, Hooper J, Poole-Wilson PA, Coats AJ, Anker SD. Deficient insulin-like growth factor I in chronic heart failure predicts altered body composition, anabolic deficiency, cytokine and neurohormonal activation. J Am Coll Cardiol 1998; 32: 3937.

6. Libera LD, Vescovo G. Muscle wastage in chronic heart failure, between apoptosis, catabolism and altered anabolism: a chimaeric view of inflammation? Curr Opin Clin Nutr Metab Care 2004; 7: 435-41.

7. Dalla Libera L, Ravara B, Volterrani M, Gobbo V, Della Barbera M, Angelini A, Betto DD, Germinario E, Vescovo G. Beneficial effects of GH/IGF-1 on skeletal muscle atrophy and function in experimental heart failure. Am J Physiol Cell Physiol 2004; 286: C138-C144.

8. Stewart S, Macintyre K, Hole DJ, Capewell S, McMurray JJ. More 'malignant' than cancer? Five-year survival following a first admission for heart failure. Eur J Heart Fail 2001; 3: 315-22.

9. Matsumoto AM. Andropause: clinical implications of the decline in serum testosterone levels with aging in men. $J$ Gerontol A Biol Sci Med Sci 2002; 57: M76-99.

10. Moriyama Y, Yasue H, Yoshimura M, Mizuno Y, Nishiyama K, Tsunoda R, Kawano H, Kugiyama K, Ogawa H, Saito Y, Nakao K. The plasma levels of dehydroepiandrosterone sulfate are decreased in patients with chronic heart failure in proportion to the severity. J Clin Endocrinol Metab 2000; 85: $1834-40$.
11. Anker SD, Volterrani M, Pflaum CD, Strasburger CJ, Osterziel KJ, Doehner W, Ranke MB, Poole-Wilson PA, Giustina A, Dietz R, Coats AJ. Acquired growth hormone resistance in patients with chronic heart failure: implications for therapy with growth hormone. J Am Coll Cardiol 2001; 38: 443- 52.

12. Kontoleon PE, Anastasiou-Nana MI, Papapetrou PD, Alexopoulos G, Ktenas V, Rapti AC, Tsagalou EP, Nanas JN. Hormonal profile in patients with congestive heart failure. Int J Cardiol 2003; 87: 179-83.

13. Al-Obaidi MK, Hon JKF, Stubbs PJ, Barnes J, Amersey RA, Dahdal M, Laycock JF, Noble MIM, Alaghband-Zadeh J. Plasma insulin-like growth factor-1 elevated in mild-tomoderate but not severe heart failure. Am Heart J 2001; 142: E10.

14. Pugh PJ, Jones RD, Jones TH, Channer KS. Heart failure as an inflammatory condition: potential role for androgens as immune modulators. Eur J Heart Fail 2002; 4: 673-80.

15. Rauchhaus M, Doehner W, Anker SD. Heart failure therapy: testosterone replacement and its implications. Eur Heart J 2006; 27: 10-12.

16. Opalinska-Ciszek E, Niemczyk S, Matuszkiewicz-Rowinska J. Prolactin (PRL), thyrotropin (TSH), free thyroid hormones (fT4), (fT3) and testosterone (TTE) level in men with chronic heart failure. Pol Arch Med Wewn 2005; 113: 320-5.

17. Ewa A. Jankowska, Bartosz B, Jacek M, Alicja S, Monika L, Piotr PL, Marek M, Anker SD, Waldemar B, Philip A. Anabolic deficiency in men with chronic heart failure: prevalence and detrimental impact on survival. Circulation 2006; 114: 1829-37.

18. Chen Q, Li XY, Li JY, Zhang WY, Li HT, Liu F. A comparative survey of sex hormones levels between elderly men with chronic heart failure and normal elderly subjects. Zhonghua Xin Xue Guan Bing Za Zhi 2005; 33: 505-8.

19. Wu HY, Wang XF, Wang JH, Li JY.Testosterone level and mortality in elderly men with systolic chronic heart failure. Asian J Androl 2011; 13: 759-63.

20. Gu "der G, Frantz S, Bauersachs J, Allolio B, Ertl G, Angermann $\mathrm{CE}$, Störk S. Low circulating androgens and mortality risk in heart failure. Heart 2010; 96: 504-9.

21. Sacca L. Heart failure as a multiple hormone deficiency syndrome. Circ Heart Fail 2009; 2: 151-6.

22. Kazi M, Geraci SA, Koch CA. Considerations for the diagnosis and treatment of testosterone deficiency in elderly men. $\mathrm{Am}$ J Med 2007; 120: 835-40.

23. Ceconi C, Boraso A, Mele D, Guardigli R, Ferrari R. TNF alpha in patients with congestive heart failure. Basic Res Cardiol 2004; 99: 12-17.

24. Ducharme A, Frantz S, Aikawa M, Rabkin E, Lindsay M, Rohde LE. Targeted deletion of matrix metalloproteinase-9 attenuates left ventricular enlargement and collagen accumulation after experimental myocardial infarction. J Clin Invest 2000; 106: 55-62.

25. Piepoli M, ClarkAL, Volterrani M, Adamopoulos S, Sleight P, Coats AJS. Contribution of muscle afferents to the hemodynamic, autonomic, and ventilatory responses to exercise in patients with chronic heart failure. Effects of physical training. Circulation 1996; 93: 940-52. 
26. Gullestad L, Aass H, Fjeld JG, Wikeby L, Andreassen AK, Ihlen H, Simonsen S, Kjekshus J, Nitter-Hauge S, Ueland T, Froland SS, Aukrust P. Immunomodulating therapy with intravenous immunoglobulin in patients with chronic heart failure. Circulation 2001; 103: 220-25.

27. Aukrust P, Yndestad A, Damas JK, Gullestad L. Inflammation and chronic heart failure-potential therapeutic role of intravenous immunoglobulin. Autoimmune Rev 2004; 3: 221-7.

28. Pugh PJ, English KM, Jones TH, Channer KS. Testosterone: a natural tonic for the failing heart? Q J Med 2000; 9: 68994.

29. Malkin CJ, Pugh PJ, West JN, van Beek EJR, Jones TH, Channer KS. Testosterone therapy in men with moderate severity heart failure: a double-blind randomized placebo controlled trial. Eur Heart J 2006; 27: 57-64.

30. Pugh PJ, Jones TH, Channer KS. Acute haemodynamic effects of testosterone in men with chronic heart failure. Eur Heart J 2003; 24: 909-15.

31. Pugh PJ, Jones RD, West JN, Jones TH, Channer KS.
Testosterone treatment for men with chronic heart failure. Heart 2004; 90: 446-7.

32. Caminiti G, Volterrani M, lellamo F, Marazzi G, Massaro R, Micelli M, Mammi C, Piepoli M, Fini M, Rosano GM. Effect of long-acting testosterone treatment on functional exercise capacity, skeletal muscle performance, insulin resistance, and baroreflex sensitivity in elderly patients with chronic heart failure a double-blind, placebo-controlled, randomized study. J Am Coll Cardiol 2009; 54: 919-27.

33. Miyamoto H, Altuwaijri S, Cai Y, Messing EM, Chang C. Inhibition of the Akt, cyclooxygenase-2, and matrix metalloproteinase-9 pathways in combination with androgen deprivation therapy: potential therapeutic approaches for prostate cancer. Mol Carcinogen 2005; 44: 1-10.

34. Zhang $Y Z$, Xing XW, He B, Wang LX. Effects of testosterone on cytokines and left ventricular remodelling following heart failure. Cell Physiol Biochem 2007; 20: 847-52.

35. Li ZB, Wang J, Wang JX, Chen XM, Jiang SS. Testosterone therapy improves cardiac function of male rats with right heart failure. Zhonghua Nan Ke Xue 2009; 15: 994-1000. 